\title{
Strategies to Address The Loss of Local Art and Wisdom in Indonesia
}

\author{
Muhammad Farid ${ }^{1 \mathrm{a}}$; Sudirman Karnay ${ }^{1}$ \\ ${ }^{1}$ Department of Communication, Hasanuddin University, Makassar, Indonesia \\ a Corresponding author: farid@unhas.ac.id
}

\begin{abstract}
This paper aims to analyze traditional art as local wisdom used as medium for communication to disseminate messages related to moral, ethic, social intercourse, and religion as well as to analyze obstacles found in traditional art. Approach to communication media is expected to discover potencies of traditional media, which still exists in certain community. Traditional media is very potential to develop, so it can be a conveyor of moralistic and ethical messages firmly held by certain community. The qualitative method is the approach used to get primary and secondary data. Interview is conducted to community leaders, who exactly know the existence of traditional media that is still used by the residents and government. Observation is applied towards two kinds of arts. It is to know whether it is still exist or it is forgotten. Data analysis uses Miles and Hubermann's interactive model, in which there is an interactive process data collection, data reduction, and data presentation. The results show that two existing media namely Tennong, Pammingki Dance, and Sere Api are traditional arts used as traditional communication media. They bring messages on religion, moral, and ethics in intercommunication. However, these arts face difficulty on their developments, as they are not taught to communities as well as do not get budget from the government.
\end{abstract}

Keywords_local wisdom, traditional media, indonesia

\section{INTRODUCTION}

In cultural aspect, particularly traditional art or communities' performances, it is mostly available and spread among various regions in Indonesia. Almost every regions have performances such as puppet show in Java, Lenong in Betawi, Madihin in Sumatrera, Sinrili in South Sulawesi and so on. Those arts still exist and keep being preserved. Although many of them are extinct, because they are not passed to the next generation. In fact, to preserve culture, it should be shall be passed to the younger generation. As explained by Liliweri culture is believed as a legacy from the adults to children [1]. That human are not born with culture, but culture is learnt by human along their life. The learning process is a part of social heredity owned by human since they were born. Therefore, if we want to learn culture, we should study social heredity of a group of people in certain culture. Traditional media has been studied since 1960 in developing countries, in Asia and Africa. The possibility to use this media was officially started. UNESCO in 1972 suggested that the systematical use of traditional media may grow motivation to cooperate with community, whose original purpose is not only for social and economic development, but also cultural development.

Message spread through traditional media is considered varied, as tradition, norms, values, advice or ethics in social intercourse. Messages on development can also be included, for example, health, cleanliness and environment. Message sent through traditional media is easily understood by community, often used to convey information on development. Community is expected to give positive response towards existing traditional media as information channel for development. Guidance and development of traditional media is expected to improve the dynamics of traditional media development on which studies and research are still conducted to restore its fame. Meanwhile, due to its familiarity and rich in variation, it is loved by people in various age and groups. It also has great potential to develop. With its simplicity, it can be used as a face-to-face medium for the people and immediate feedback. Traditional art or people performances are local cultural identity, which should get attention from local government, because many have been extinct and would become extinct. This art is spread in various villages in Indonesia, mainly in remote villages, which are not exposed by mass media. This paper aims to analyze traditional art as local wisdom, used as traditional media of communication to disseminate messages related to moral, ethic, social intercourse, and religion as well as to analyze obstacles found in traditional art as local wisdom to used as traditional media of communication to disseminate messages related to moral, ethic, social intercourse, and religion.

\section{METHOD}

\section{A. Focus and Instrument}

Focus discussed in this research is related to research problems / research objectives includes: Traditional Art in Pangkep and Barru District; A Review of Perspective Traditional Communication Medium. Related to Traditional Art in Pangkep and Barru District; A Review of Perspective Traditional Communication Medium, we make human as research instruments to try to collect data. In addition, we also use other instruments to support such as interview, observation and data documentation guidelines. To collect data, we use camera and recorder to complete weak instruments. 


\section{B. Data Collection}

In accordance with the open and flexible nature of the qualitative research, method and type of data collection in qualitative research is very diverse, adapted to the problem, research objectives, and the nature of the object under study. the researcher made direct observation on a number of phenomenon relevant to the purpose of the study: how the public interest in witnessing every traditional art show is and how the role of community leader encourages its citizens to preserve the traditional arts. This research was conducted in depth interview, a form of interview that flows on the strength of informant in explaining his experience in accordance with the focus excavated from each informant that is done without preparing a rigorous list. Interview with informant, such as traditional figure/community leader, player, Head of Education Board.

\section{RESULT AND DISCUSSION}

\section{A. Results}

There are three traditional arts that are still utilized by people in Pangkep and Barru: Tennong in Bungoro Pangkep and Pammingki in Pangkajene Pangkep as well as Sere Api in Barru. Those are still often staged in any traditional events held in the district.

Pammingki Dance, particularly, is included in the customary event: down into the rice field. Pakkarena Dance is an art fusion of dance and sound accompanied by traditional instruments like pakarena drum, gong bacing/tawa tawa, and puwi puwi with 12 all-men Pakarena players as the dancers; hence they are also called Pakkarena Burakne (Male Pakkarena).

Pammingki was not spread throughout the territory of Pangkep and confined only to certain area. Likewise, Tennong was already spread limitedly to specific villages. This problem was due to inexistence of potential cadres to teach this art.

Tennong music was first discovered in 1969 at the moment Tabo-Tabo dam was being established. It was initially found in a corn field by the keeper. Approaching, he saw it played by a little girl with her brother. By the time, this instrument had not been named yet. Nevertheless, there were clearly seven pieces of wood placed on the girl's thigh, played with two small wood sticks. Her brother plucked the harp while singing Indologo. Apparently these two children played a musical instrument to entertain themselves while keeping the vermin away.

Before the existence of television in the village, this form of art used to be played all the time and the melody was often heard. In short, this instrument became a medium of entertainment and part of their lives at the time. However, today is different than those days. Tennong is only played at celebration event.

Nevertheless, the government always attempts to preserve this art. Tennong players are always invited to perform in every important event in the district, for example, annual development exhibition, celebration of the day of independence, welcome performance for guests visiting Pangkep.
Tennong as traditional communication media can adapt to the situation by art performance. This becomes a distinctive attraction. Moreover, the original songs are able to fascinate the audience such as Anak Beue, Bulu Alauna Mekka, and so on.

Play of Sere Api, originally from Gattareng Barru, first appeared when the locals started farming, especially paddy field. Since the performance was related to annual folk's harvest festival, there is no clear data about when it was found and performed for the very first time. Nonetheless, according to various folklore, in the era of independence, this art was already performed but in a very simple way: only Mappadendang performance by mashing a mortar using pestle as a symbol that soon the village would be bustling with people pounding newly harvested paddy.

Messages conveyed by Pammingki and Sere Api are still limited to certain matters and have not developed in line with expectations since no individual nor even the players try to compose songs adjusted to the interest today. Similarly, Tennong's songs tend to be monotonous.

All players of Tennong, Pammingki, and Sere Api are no longer at their young age. They are also low-educated and, hence, unable to improvise well and in the end of the day their performance seems less vibrant. The messages conveyed are only enjoyed by the locals and when performed in other place, it will be less adaptable. Lack of education clearly affects the players' creativity.

The government's role in conducting training is considered not maximized. Budget scheming and development programs hardly ever include these forms of art.

The institute involved in wide dissemination to the public, especially to elementary school students to learn them as local content subject, is limited only to the school adjacent to the location of these local arts. While Tennong studied in some elementary schools in Bungoro, where Tennong originally comes from, Pammingki is only socialized and has not been included as local content subject.

Competition or exhibition of these arts was never conducted. It is only to entertain public on certain festive celebrations, like celebration of $17^{\text {th }}$ of August and other celebrations. Moreover, it is only performed in the place of its origin.

\section{B. Discussion}

Some villages are still far from the reach of mass media, both newspaper and television due to geographical conditions that disallow people to access the media, especially the television, so the only media that can be used to receive messages is traditional media. As stated by Hanafi [2], a lot of things determine media options, which are limited to: 1) what kind of media available; 2) how much money we have; 3) media preferences.

Tennong, Pammingki, and Sere Api are alternatives to convey messages, ethical, moral, social, and religious contents. This media is remarkably familiar and close to the community so the messages delivered are understandable. 
These three forms of art have been popular in the community for their performance contains messages of advices, suggestions, and social life of the youth, through their catchy and understandable songs to the audience where the same socio-cultural background between the players and community exists. Simon affirms why communicators perceived to have things in common tend to communicate more effectively [3]. First, similarity simplifies decoding, a process of translating received symbols into ideas. Second, similarity helps build the same premise, which facilitates deductive process. This means when the dispositional similarity is relevant to the topic of persuasion, people will be affected by the communicator. Third, things in common cause communicant to be interested in the communicator. Fourth, similarity fosters respect and trust toward the communicator.

It is necessary to note that the similarity between communicator and communicant largely determines the success of a communication. According to Rakhmat, when a communicator communicates, what affects is not only what he says but also what he is [3]. "He doesn't communicate what he says, he communicate what he is". He cannot tell the listeners to only pay attention. They will also pay attention to the person delivering it. Sometimes 'who' matters more than 'what'.

Tennong, Pammingki, and Sere Api may function double as entertainment and communication channel. As entertainment, Tennong and Pammingki deliver the players' or folk songs, which are favored by the people. These songs occasionally touch their listeners. For example, Beue, a children song, is about a young man left behind by both of his parents. He figured out his own life tingled with endless waves and tides.

Tennong can be played when alone as well as in a festive gathering. The rural community is very pleased to have Tennong for it is the only entertainment for them.

As communication channel, its function is to convey messages delivered by the player himself and it could be played all night long. To convey the message of development, the script must be translated into Makassar or Bugis language and then chanted along with the beat of Tennong. Message can be delivered individually or by group.

Tenong, Pammingki, and Sere Api utilized to channel all the messages were born and grew abundantly in the midst of society with its purpose as a mean of communication with a goal: through this media, values, morals, and culture of the rural community can be enhanced.
Performance of Tennong, Pammingki, and Sere Api plays a great role to strengthen the cultural values. It can also sensitize the target to the prevailing norms and at the same time propagate new development ideas to stimulate community participation in it.

According to Susanto, an analysis on traditional media proved that its success and effectiveness were mainly determined by its nature with strong interaction with public [4]. Communicator must have a strong empathy toward public and enable them to participate in the show.

As traditional media, Tennong, Pammiki, and Sere Api have inherent characteristics, one of which the touches of their catchy songs accompanied with singing in harmony with the surroundings where this performance takes place.

People show positive response to these traditional media and it is likely to be improved in the future.

In the end, it is recognizable that public is so pleased with these media to deliver messages that they are expected to work along with the modern media to spread either development or specific information.

\section{CONCLUSION}

The study found that as a favored medium growing and existing among the society, Tennong, Pammingki Dance and Sere Api are traditional arts often utilized as traditional communication media to convey certain messages to citizens such as moral, ethic, and religion. To distribute the messages of development, it requires a special formulation by adjusting the rhythm and the song. These three arts are facing obstacles in its advancement as it is not popularized throughout Pangkep and Barru. The government does not provide any particular budget to develop these two traditional arts.

\section{REFERENCES}

[1] A. Liliweri, Makna Budaya dalam Komunikasi Antarbudaya. Jogyakarta: LKiS, 2003.

[2] A. Hanafi, Memahami Komunikasi Antar Manusia, Usaha Nasional Surabaya, Indonesia, 1984.

[3] J. Rakhmat, Metode Penelitian Komunikasi. Bandung: Remadja Karya, 1985.

[4] S,A. Susanto, Komunikasi Kontemporer, Bandung: Bina Cipta Bandung, 1982. 